\title{
DIALOGLE \\ Annual Meeting Offers Variety, Depth, and Interdisciplinary Science
}

\author{
John Geissman, Technical Program Chair, GSA 2002 Annual Meeting
}

contemporary geomorphology, and exploration of the solar system.

\section{Greetings (Again)}

With more than 125 topical sessions and seven Pardee Keynote Symposia spanning a broad range of interests and reflecting a healthy emphasis on interdisciplinary geoscience, the 2002 Annual Meeting in Denver promises an excellent forum for communication of quality geoscience.

Three Pardee symposia focus on highly topical, as well as pleasantly contentious, policy-related issues that will keenly affect our society for years to come.

(2) "Earth Sciences Challenges in the National Problem of HighLevel Radioactive Waste Disposal" (Monday morning) will address major issues bearing on the suitability of a mined repository.

(อ) "The Role of the Earth Sciences in Fostering Global Equity and Stability" (Monday afternoon) explores the critical issue of the contribution of earth sciences in effecting a globally sustainable planet.

(-) "Toward a Better Understanding of the Complicated Earth" (Tuesday afternoon), sponsored by the National Association of Geoscience Teachers, will deal with how to better understand our home through increasing our ability to affect the learning process

Four Pardee symposia highlight cuttingedge science on Earth's early evolution,
() Two surface-processes-oriented symposia will focus on landscape evolution (Sunday morning) and flood hazards on dynamic rivers (Wednesday afternoon).

() A symposium on the evolution of the early Earth environment as recorded in Precambrian ore deposits (Tuesday morning) will summarize the wealth of new information that bears on how environmental conditions

(2) With growing hope that future, current, and recent graduates in the geosciences may play a keen, active role in the exploration of Mars, the symposium "There and Back Again: Terrestrial Approaches to Extraterrestrial Problems" (Wednesday morning) serves as a steppingoff point for evaluation of anticipated extraterrestrial dilemmas and how to deal with them.

The 127 Topical Sessions provide a great mix of science and attractive representation for most geoscience disciplines.

Several sessions (e.g., T84, "Seafood Through Time," honoring Richard Bambach) will celebrate the scientific accomplishments of notable individuals in the geosciences. These sessions will present new science as well as overviews of the history of progress in these fields.

The Middle East - a relatively poorly known part of the world, geologically changed on Earth. speaking-has been the subject of intense interest of late. The session "Tectonic Evolution of the Middle East and Adjacent Regions" will focus on links between the Alpine and Himalayan orogenic systems.

Exploring a topic that has long been of keen interest, several sessions on Rocky Mountain evolution have been organized into a sequence that could informally be referred to as "Building and Tearing Down the Rocky Mountains!” These sessions will involve numerous approaches to solving this fundamental issue in western Cordilleran geology.

Several sessions promise interesting interdisciplinary fare. Paleontological Society-sponsored sessions include T76, "Three Billion Years of Reef Systems," and T81, "Paleobiogeography: Integrating Plate Tectonics and Evolution."

Following on themes from last year's groundbreaking GSA-Geological Society of London meeting in Edinburgh, sessions T71, "Feedback in Earth Systems: Determining System Response to Perturbation Through Observations and Modeling," and T73, "Global Biogeochemical Change During PETM Events," will concentrate on many facets and offer discussion of earth system processes.

Please plan to join us-and many of your colleagues - and contribute to Denver 2002-Science at the Highest Level, the 114th Annual Meeting and Exposition of the Geological Society of America. Please note that the abstract deadline is July 16 ! 